\title{
Microfluidic assisted self-assembly of pH-sensitive low- molecular weight hydrogelators close to the minimum gelation concentration
}

Citation for published version (APA):

Hermida-Merino, D., Trebbin, M., Foerster, S., Rodriguez-Llansola, F., \& Portale, G. (2015). Microfluidic assisted self-assembly of $\mathrm{pH}$-sensitive low-molecular weight hydrogelators close to the minimum gelation concentration. Macromolecular Symposia, 358(1), 59-66. https://doi.org/10.1002/masy.201500032

DOI:

10.1002/masy.201500032

Document status and date:

Published: 01/12/2015

Document Version:

Publisher's PDF, also known as Version of Record (includes final page, issue and volume numbers)

\section{Please check the document version of this publication:}

- A submitted manuscript is the version of the article upon submission and before peer-review. There can be important differences between the submitted version and the official published version of record. People interested in the research are advised to contact the author for the final version of the publication, or visit the DOI to the publisher's website.

- The final author version and the galley proof are versions of the publication after peer review.

- The final published version features the final layout of the paper including the volume, issue and page numbers.

Link to publication

\footnotetext{
General rights

- You may freely distribute the URL identifying the publication in the public portal. follow below link for the End User Agreement:

www.tue.nl/taverne

\section{Take down policy}

If you believe that this document breaches copyright please contact us at:

openaccess@tue.nl

providing details and we will investigate your claim.
}

Copyright and moral rights for the publications made accessible in the public portal are retained by the authors and/or other copyright owners and it is a condition of accessing publications that users recognise and abide by the legal requirements associated with these rights.

- Users may download and print one copy of any publication from the public portal for the purpose of private study or research.

- You may not further distribute the material or use it for any profit-making activity or commercial gain

If the publication is distributed under the terms of Article $25 \mathrm{fa}$ of the Dutch Copyright Act, indicated by the "Taverne" license above, please 


\title{
Microfluidic Assisted Self-Assembly of pH-Sensitive Low-Molecular Weight Hydrogelators Close to the Minimum Gelation Concentration
}

\author{
Daniel Hermida-Merino, ${ }^{* 1,2}$ Martin Trebbin,${ }^{3}$ Stefan Foerster,${ }^{4}$ Francisco Rodriguez- \\ Llansola, ${ }^{5}$ Giuseppe Portale ${ }^{1}$
}

Summary: The fibrillation and subsequent gelation of low molecular hydrogelators is usually triggered by external stimuli. Generally, strong acids are employed to trigger the self-assembly mechanism in $\mathrm{pH}$-responsive supramolecular systems. However, the generation and design of novel stable gels with performing mechanical properties is a challenging task as a result of the uneven self-assembled networks formed. Here, we report the study of the self-assembly process of a low molecular weight hydrogelator (LMWG) in the proximity of its minimum gelation concentration $(\mathrm{MGC}=0.3 \mathrm{mg} / \mathrm{ml})$. At such high dilution, the generation of homogeneous gels with good mechanical properties by turning $\mathrm{pH}$ by strong acids is a demanding task as a result of the lack of monodisperse $1 \mathrm{D}$ self-assembled rod-like aggregates. A microfluidic device is employed here to gradually and homogeneously change the $\mathrm{pH}$. We show that self-assembly of LMWG in welldefined structures can be enhanced by using the diffusive mixing occurring in the microfluidic reactor channel. For very short mixing times, aggregates with $2 \mathrm{~nm}$ cross-section are found in the region adjacent to the focused LMWG solution in contact with the low $\mathrm{pH}$ buffer solution streams, where the $\mathrm{pH}$ reaches values below the pKa of the LMWG and triggers the supramolecular self-assembly. For longer mixing times, aggregates grow in size and occupy homogeneously the micro channel. The results presented here show that better controlled self-assembly can be achieved using microfluidic mixing devices and early stages of self-assembly can be efficiently studied by coupling synchrotron SAXS with microfluidics.

Keywords: gelation; microfluidic devices; pH sensitive supramolecular gelators

\footnotetext{
${ }^{1}$ DUBBLE CRG BM26 ESRF, Netherlands Organization for Scientific Research, ESRF-The European Synchrotron, 71, Avenue des Martyrs, Grenoble, France

E-mail: hermidam@esrf.fr

2 Dutch Polymer Institute DPI, P.O. Box 902, Eindhoven $5600 \mathrm{AX}$, The Netherlands

${ }^{3}$ Department of Physics, University of Hamburg, Centre for Ultrafast Imaging (CUI) Hamburg, Germany

${ }^{4}$ Physical Chemistry I, University of Bayreuth, Bayreuth 95447, Germany

5 Institute for Complex Molecular Systems and Laboratory of Macromolecular and Organic Chemistry, Eindhoven University of Technology, P.O. Box 513, Eindhoven $5600 \mathrm{MB}$, The Netherlands
}

\section{Introduction}

Physical gels have been suggested as pioneer candidates for different research fields and as smart materials for a broad range of applications such as drug delivery, catalysis, sensing photonics, tissue engineering and filtering materials. ${ }^{[1-3]}$ The desired responsive nature to external stimuli relies on non-covalent interactions that define the thermodynamic and physical properties of physical gels. ${ }^{[4]}$ Physical gels are typically obtained through the self-assembly of specific moieties of chemical systems triggered by $\mathrm{pH}$ or temperature changes. In general, monodisperse supramolecular entities featuring well-defined 
structures are required to conduct selective tasks, similarly to what is found in nature. However, the sequential synthetic steps of supramolecular entities depend dramatically on the thermodynamic environment of the medium and subtle changes will dramatically impact the final structure. ${ }^{[5]}$ The control at the nanoscale of the external stimuli across the solution involves challenging equipment and in particular for $\mathrm{pH}$-triggering systems remains generally unfeasible. Organogels quenched at fast cooling rates usually lead to defects in the self-assembly process, yielding kinetically trapped structures or different polymorphs. In contrast, slow cooling rates provide the system thermodynamic stability to afford well-defined material with improved physical properties. Similarly, the self-assembly mechanism of $\mathrm{pH}$ responsive systems is considerably affected by the $\mathrm{pH}$ turning method. Several methods were employed in the past to change the $\mathrm{pH}$, such as direct addition of acids, or bases, red-ox reactions and diffusion of volatile acids or bases. Adams et al. ${ }^{[6]}$ have recently showed that the use of the slow hydrolysis of glucono$\delta$-lactone to gluconic acid as a method for decreasing the $\mathrm{pH}$ in a controlled fashion allows the preparation of supramolecular gels with improved properties. The addition of glucono- $\delta$-lactone has been largely employed in the last 5 years to control the morphology of the fibres obtained by modifying the $\mathrm{pH}$ medium at local scale. ${ }^{[6-9]}$

Extensive studies on the early stages of the formation of physical gels are crucial to underpin the main structural criteria that later defines both the mechanical properties ${ }^{[10]}$ and responsive nature of the obtained self-assembled materials. The mechanism of self-assembly of a $\mathrm{pH}$-sensitive low molecular weight hydrogelator (LMWG) has proved the crucial importance of the control of the $\mathrm{pH}$ turning at the local scale to generate monodisperse well-defined fibers.

Understanding fibrillation in nanomedicine, is a major concern in the advance of neurodegenerative diseases such as Parkinson and Alzheimer associated with amyloid fibrils formation, attracting great interest to the formation of polypeptides assemblies. ${ }^{[11]}$
Polypeptides were largely selected to generate protein-like materials ${ }^{[12]}$ to explore the fibrillation mechanism inherent to the peptide-assembly from the initial assembly, transient morphological stages to the final fibrillar structure. ${ }^{[13]}$ Low molecular weight organic gelators (LMWG) offer an alternative synthetic route to obtain highly controlled fibrillar architectures. ${ }^{[14]}$

Microfluidic flow reactors can be potentially employed to control the $\mathrm{pH}$ medium at the nanoscale by controlling the flow of different $\mathrm{pH}$ solutions and different concentrations of the LMWG solution. Microfluidic platforms allowing mixing have been proved to be excellent tools to study protein denaturation, ${ }^{[15]}$ protein fibrillation, ${ }^{[16]}$ RNA refolding. ${ }^{[17]}$

Microfluidic flow reactors could thus be used as a substitute to chemical species to modify the $\mathrm{pH}$ at the nanoscale in a controlled fashion avoiding heterogeneous detrimental competing effects during the addition of strong acids. Importantly, at each point of the microfluidic device, the self-assembly is a steady state process allowing to easily monitor the self-assembly mechanism in a static fashion. The system evolution is only a function of the mutual distances from the contact point of two or more flowing solutions. Moreover, the modification of the design of microfluidic flow reactors offers the possibility to generate novel materials with wide broad applications such as wound treatment, tissue engineering and drug delivery. ${ }^{[18,19]}$ Thanks to intense X-ray micro beams provided nowadays on most of the $3^{\text {rd }}$ generation synchrotrons, we show here the combination of small angle X-ray scattering (SAXS) technique with a microfluidic mixing flow reactor to probe the formation of the self-assembled LMWG fibers at the different stages of the fiber formation.

\section{Experimental Section}

SAXS experiments were performed at the Dutch-Belgian Beamline (DUBBLE) station $\mathrm{BM} 26 \mathrm{~B}^{[20]}$ of the European Synchrotron 
Radiation Facility (ESRF) in Grenoble (France) with a microbeam of ca. $20 \times 20 \mu \mathrm{m}$ produced by a post focusing Kirkpatrick-Baez system. SAXS patterns were recorded by a $300 \mathrm{~K}$ linear Dectris Pilatus detector with an active area of $254 \mathrm{~mm} \times 33.5 \mathrm{~mm}$ and pixel size of $172 \times 172 \mu \mathrm{m}$. The sample-to-detector distance was fixed to $215 \mathrm{~mm}$ and a wavelength of $1.033 \AA$ was selected. The wavenumber $q=4 \pi / \lambda \sin \theta$ scale for the SAXS experiments was calibrated employing the diffraction peaks from a standard alpha aluminum powder. Standard corrections for sample absorption and background subtraction have been performed to the acquired data. The SAXS profiles were normalized with respect to the incident beam intensity in order to correct for primary beam intensity fluctuations.

Hydrogelator 1 (5-(3-(4-nitrophenyl) ureido) isophatalic acid) was synthesized following the procedure reported earlier. ${ }^{[21]}$

A $0.5 \mathrm{gr} / \mathrm{ml}$ LMWG was dissolved in an excess of aqueous $\mathrm{NaOH}$ solution to yield basic solutions $(\mathrm{pH}=14)$ A $\mathrm{pH} 2 \mathrm{HCl}$ solution was prepared to acidify the LMWG solutions.

A microfluidic device made of X-ray transparent NOA81 (Norland Optical Adhesive) was used for the SAXS experiments. The microfluidic device has been obtained according to the procedure described elsewhere. ${ }^{[22,23]}$ The channel dimensions of the microfluidic device were $300 \times 100 \mu \mathrm{m}$ (width $\times$ height). The LMWG and HCL solutions were flown using a high-precision syringe pumps (Nemesys system; Cetoni $\mathrm{GmbH}$ ) with a pumping rate of $100 \mu \mathrm{l} / \mathrm{h}$ for the LMWG solution (main channel, MC), and $200 \mu \mathrm{l} / \mathrm{h}$ for the $1 \mathrm{M} \mathrm{HCl}$ solution (side channels, SC). The flow velocity in the main channel (MC) can be obtained as $v_{\text {tot }} / \mathrm{A}$, where $v_{\text {tot }}$ is the total volumetric flow given by $\left(v_{\mathrm{MC}}+2 v_{\mathrm{SC}}\right)$ and $\mathrm{A}$ is the main channel cross-section. According to our conditions, the flow velocity was $4.7 \mathrm{~mm} / \mathrm{s}$.

The $\mathrm{pH}$ map inside the microfluidic device at the same flow conditions used for the experiments has been simulated using the CFD-software package COMSOL, using a proton diffusion coefficient of $4.7 \mathrm{e}-10 \mathrm{~m}^{2} / \mathrm{s}$.

\section{Results and Discussion}

Physical gels are typically characterized by a spanning network of fibers that generally shows a branched structured at the nanoscale, responsible of the macroscopic properties of the system. Gels formed by highly branched fiber networks are translucent whilst single network fibers generate transparent gels. ${ }^{[6]}$

The structure of physical gels is defined by both the thermodynamical conditions of the developing medium and the molecular structure of the supramolecular gelator. The supramolecular gelator structure determines the self-assembly capabilities that can generate different self-assembled entities ${ }^{\text {[24] }}$ whilst the medium delineates the growing cluster and governs the association rate. Moreover, uncontrolled nanoscopic $\mathrm{pH}$ change creates inhomogeneous systems that present irregular structures featuring highly branched networks. ${ }^{[25]}$

Recently, the structural investigation of a solvatochromic low molecular weight hydrogelator LMWG 1 (see Figure 1) has enabled $^{[21]}$ us to examine the concomitant dependence of both fiber structure and fibrillar network morphology on the medium. The high insolubility in water of LMWG 1 can be overwhelmed by a cosolvent or basic $\mathrm{pH}$ medium. Once the supersaturation point is reached either by

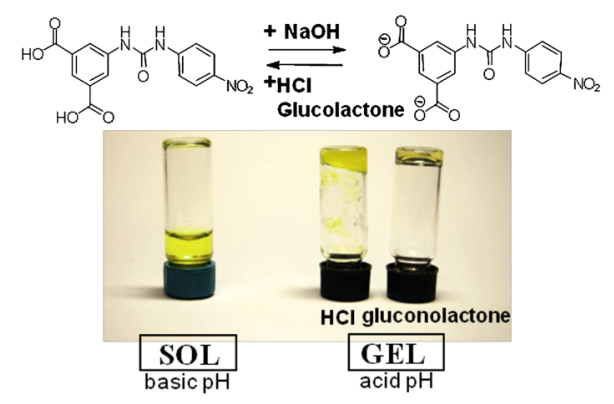

Figure 1.

Macroscopic differences of the gels formed LMWG $\mathbf{1}$ by $\mathrm{HCl}$ addition or slow hydrolysis of glucono- $\delta$-lactone. 


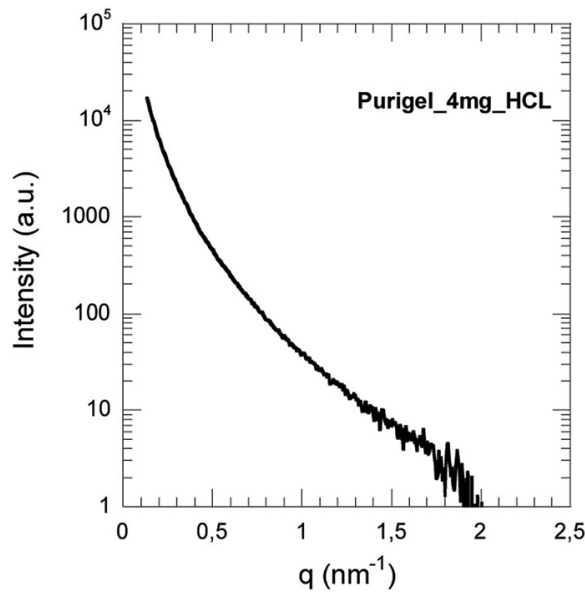

Figure 2.

SAXS profiles gels formed by LMWG by addition of a solution of $\mathrm{HCl}$.

the addition of a cosolvent or upon $\mathrm{pH}$ changes the system gels.

Needle-like crystals were obtained ${ }^{[21]}$ by slow evaporation of a solution $70 / 30 \%$ $\left(\mathrm{H}_{2} \mathrm{O} /\right.$ methanol) whilst important visual differences were observed in the final gels when turning the $\mathrm{pH}$ either by the $\mathrm{HCl}$ addition or by glucono- $\delta$-lactone hydrolysis (see Figure 1).

Gels formed by $\mathrm{HCl}$ addition are generally turbid and not homogeneous. On the contrary, gels obtained using glucono- $\delta$-lactone are transparent, homogeneous and extremely stable over time.

The fiber network structure of the gel formed by $\mathrm{HCl}$ addition was investigated by SAXS (see Figure 2). A highly branched fibrillar network produced by the structural local mismatch typical of systems that evolved in an uncontrolled thermodynamic fashion was revealed. In contrast, we anticipate that the gel obtained using glucono- $\delta$ lactone is characterized by highly monodisperse long fibers with extremely low degree of branching. A manuscript describing in detail the formation of the monodisperse fibers by controlling the $\mathrm{pH}$ media by the addition of glucono- $\delta$-lactone is under preparation.

However, the incipient morphology of the self-assembled LMWG system that defines the internal structure of the fibers is generally unknown and is required to gain an insight of the structural changes that occur during fibrillation. Understanding the early stages of the LMWG selfassembly around the minimum gelation concentration (MGC) at controlled kinetic and thermodynamics conditions are crucial to unveil the formation mechanism. ${ }^{[26]}$ The study of the self-assembled structures formed at a $0.5 \mathrm{mg} / \mathrm{ml}$ (in proximity of MGC) by lowering the $\mathrm{pH}$ by the addition of $\mathrm{HCl}$ solution in a microfluidic device will be investigated.

Microfluidic reactors offer an alternative methodology to control locally the thermodynamic conditions to attain the supersaturation point during the $\mathrm{pH}$ change throughout the solution. The laminar flow and the diffusion driven $\mathrm{pH}$ change in extremely small volumes and offers the opportunity to change homogeneously the $\mathrm{pH}$ along the microchannel.

The design of the microfluidic reactor permits to flow constantly a solution of $\mathrm{HCl}$ sideways whilst a basic solution $0.5 \mathrm{mg} / \mathrm{ml}$ of the LMWG 1 was introduced by the main channel (see Figures 3 and 4a). a)

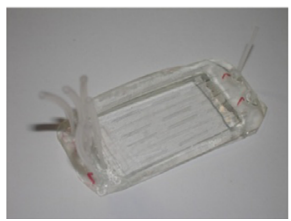

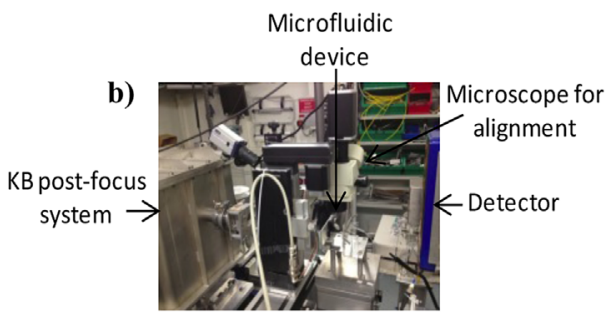

Figure 3.

(a) Microfluidic flow reactor and (b) KB mirror setup with the microfluidic flow reactor. 

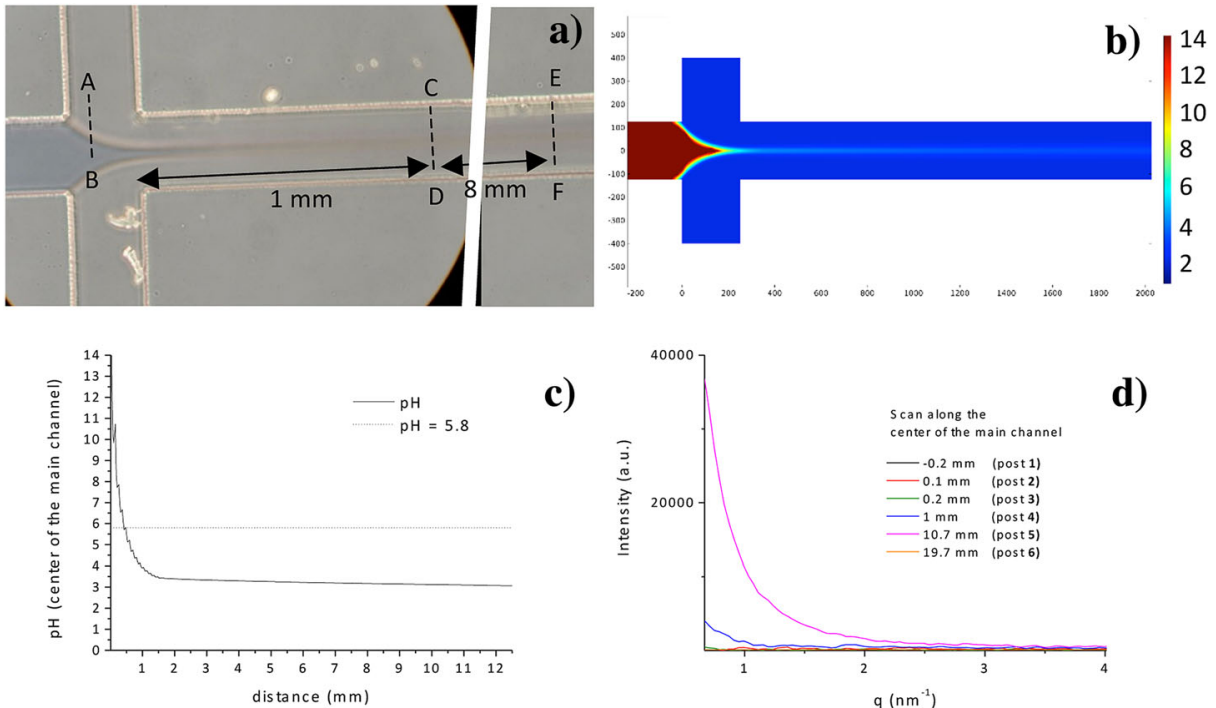

c)
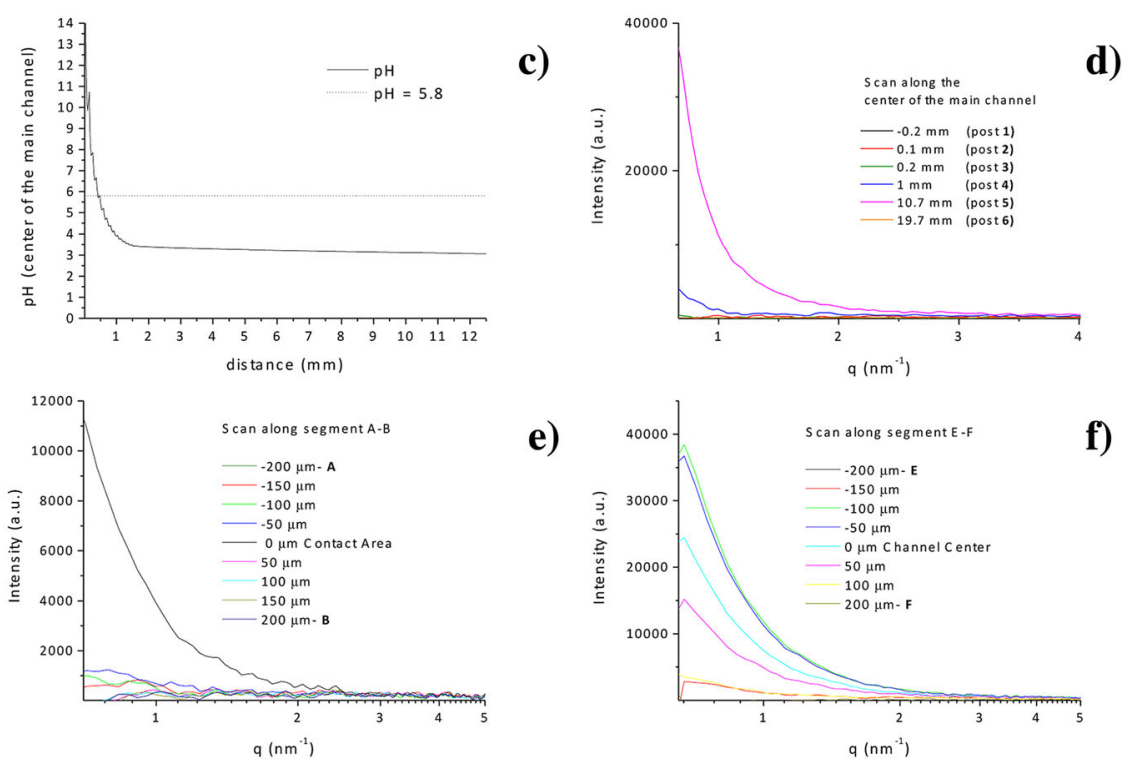

\section{Figure 4.}

a) Optical microscopy image of the flow through the microfluidics device using bromothymol blue as $\mathrm{pH}$ indicator with flow rates $100 \mu \mathrm{l} / \mathrm{h}$ in the $\mathrm{CC}$ and $200 \mu \mathrm{l} / \mathrm{h}$ in the side channel. b) COMSOL simulation of the $\mathrm{pH}$ change upon proton diffusion in water through the microfluidic device. c) Simulated $\mathrm{pH}$ along the center of the main channel at different distances of the contact point, the dashed line indicates the pKa of the LMWG 1. d) SAXS profiles of the scan along the center of the main channel. e) SAXS profiles of the scan across the channel of the microfluidic flow reactor along the segment $A-B$ of the acid and LMWG solutions (earlier stages) and $f$ ) along the segment $\mathrm{E}-\mathrm{F}$ at the end of mixing of both solutions. The position of each SAXS profile is defined accordingly to the center of the scan along the segment under study.

The design allows to acidify the LMWG solution, reaching the protonation $\mathrm{pH}$ homogeneously (ca. $\mathrm{pH}=5.8$ ) of the LMWG $\mathbf{1}$ at the contact point of the LMWG 1 and $\mathrm{HCl}$ solutions that will trigger the self-assembly of the LMWG $\mathbf{1}$. Moreover, the monitoring of the fibrillation process can be probed in a static fashion on the microfluidic device.

However, micrometer sized X-ray beams are required to map out the fiber morphology during the flow path as a result of the small channels dimension. The post focusing Kirkpatrick-Baez system (KB mirrors, see Figure $3 \mathrm{~b}$ ) produces a micro beam (ca. $20 \times 20$ microns) at a fixed focal distance that allows to conduct in situ SAXS experiments as well as scanning the microfluidic device along the flow path.

In situ SAXS experiments were conducted in order to correlate the fiber formation with the mechanism of the self-assembled LMWG (see Figure 4).

The microfluidic device permits to obtain a contact layer where the LMWG and $\mathrm{HCl}$ solutions interdiffuse 
homogenously, yielding an infinitesimal volume with an even $\mathrm{pH}$ change. The typical $\mathrm{pH}$ change occurring during the experiment was simulated by flowing bromothymol blue as $\mathrm{pH}$ indicator through the main channel and $\mathrm{HCl}$ solutions with $\mathrm{pH} 2$ through the side channels at the same flow rates used for the experiments (see Figure 4a). Bromothymol blue turns yellow when $\mathrm{pH}$ is below 6 and blue above $\mathrm{pH}$ 7. During the transition from $\mathrm{pH}$ 7 to $\mathrm{pH} 6.4$, the solution presents a green color. Figure 4a shows that a well-defined contact layer between the two solutions is established. The proton diffusion is such that most of the $\mathrm{pH}$ change in the center of the main channel is completed in the first 250-300 $\mu \mathrm{m}$ away from the point where the solutions merged for the first time (time $=$ zero). Accurate values of $\mathrm{pH}$ at each point of the microfluidic device can be estimated from the proton diffusion in water by COMSOL simulations (see Figure $4 b$ ). Simulations are in excellent agreement with the bromothymol blue experiment. The final $\mathrm{pH}$ at the contact point of the interdiffuse infinitesimal volume depends both on the solution concentrations and flow rates.

SAXS profiles were acquired across the channel widths (see Figure $4 \mathrm{e}$ and $\mathrm{f}$ ) of a mixing solution formed by a $0.5 \mathrm{gr} / \mathrm{ml}$ LMWG NaOH (pH 14) and the corresponding $\mathrm{HCl}(\mathrm{pH} 2)$ solutions (see Figure 4a, segments A-B, C-D and E-F). At the initial stage of the mixing flows (segment $\mathrm{A}-\mathrm{B}$, see Figure $4 \mathrm{a}$ and $\mathrm{e}$ ), fibrillar aggregates were only found in the contact layer between the LMWG and the $\mathrm{HCl}$ solutions. Along the scan A-B, a well-defined contact layer is formed between the two solutions where the $\mathrm{pH}$ changes rapidly between 10 and 4 . Importantly, the protonation of LMWG 1 at ca. $\mathrm{pH} 5.8$ triggers the self-assembly process as the supersaturation condition is attained.

Remarkably, no fibers have been observed at different positions across the initial intersection of the LMWG and the $\mathrm{HCl}$ as a $\mathrm{pH}$ below 5.8 was not reached. However, fiber-like structures have been found across the whole width of the channel at a later stage (segments $\mathrm{C}-\mathrm{D}$ and $\mathrm{E}-\mathrm{F}$ ), when complete mixing of both solutions was achieved and a final $\mathrm{pH}$ value around 3 is reached (see Figure $4 \mathrm{a}$ and $\mathrm{f}$ ).

Furthermore, dilution of the LMWG fibers occurs besides the $\mathrm{pH}$ change. A scan $19.7 \mathrm{~mm}$ away from the first contact point between solutions have confirmed the absence of assembled fibers as the final LMWG concentration is below the MGC (see Figure 4d).

The extent of the self-assembly process can be monitored by following the evolution of the scattered invariant during the X-ray scans (see Figure 5). The relative invariant $Q$ is defined in the measured scattering range as:

$Q=\int_{q_{1}}^{q_{2}} I(q) q^{2} d q$

where $I(q)$ is the scattered profile and $q_{1}$ and $q_{2}$ are the minimum and maximum accessible wavenumbers. The $Q$ invariant obtained across the scanned segment $\mathrm{A}-\mathrm{B}$ confirms that fibers were only observed at the contact layer of the early stages (segment A-B). However, fibers were present across the a)

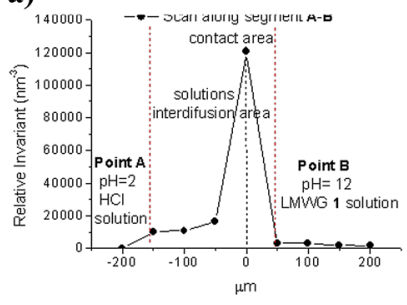

b)

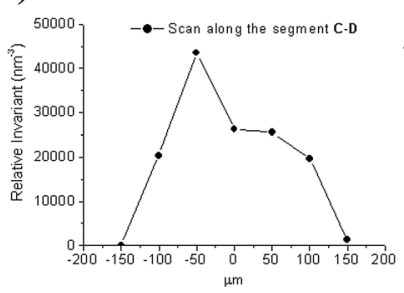

c)

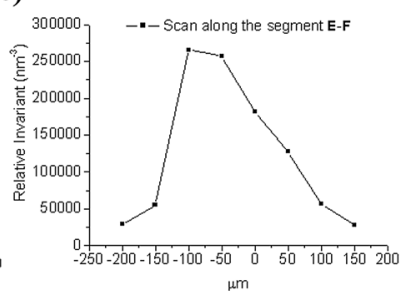

Figure 5 .

SAXS invariant for the scans across the channel along the segments a) A-B, b) C-D and C) E-F. 
a)

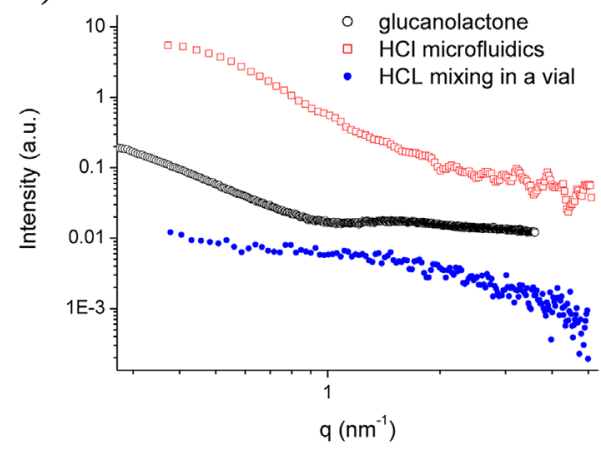

b)

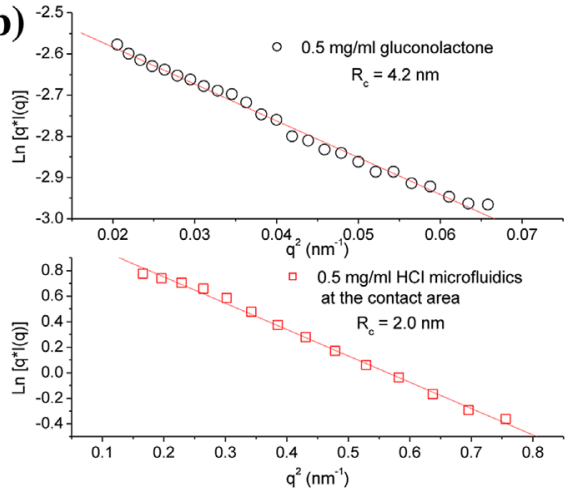

\section{Figure 6.}

a) SAXS profiles of the self-assembled LMWG with different preparation methods b) Guinier region.

whole channel width at later stages (segment $\mathrm{C}-\mathrm{D}$ and $\mathrm{E}-\mathrm{F}$ ) as the $\mathrm{pH}$ was below the $\mathrm{pKa}$ of LMWG 1 across the whole channel.

Insights on the aggregate structure at the early stages of the diffusion controlled self-assembly process can be obtained by comparing the SAXS profiles of the aggregates obtained with different methodologies and thus, diverse thermodynamical frameworks.

The SAXS profiles confirmed the nanostructural differences responsible of the observed heterogeneous macroscopic properties (see Figure 6a). The $\mathrm{pH}$ change controlled by the slow hydrolysis of glucono- $\delta$-lactone produced well-defined monodisperse fibers. Self-assembled aggregates with rod-like aspect were generated in the microfluidics reactor. However, poorly defined aggregates were obtained by the addition of $\mathrm{HCl}$ into a solution of LMWG 1 into a vial.

For rod-like aggregates, the cross-section of the scattering objects can be obtained using the Guinier law:

$$
I(q)=I(0) \exp \left(-q^{2} R_{c}^{2} / 2\right)
$$

After linearization of the Guinier law and linear fit of the experimental points, the angular coefficient yields the cross-section radius $R_{c}$.

Interestingly, the differences on the cross-section radius at neighboring concentrations to MGC of the fibers obtained in the microfluidic device $(2 \mathrm{~nm})$ compared to the fibers generated by glucono- $\delta$-lactone $\mathrm{pH}$ change $(4 \mathrm{~nm})$ confirms that subtle changes on the thermodynamic framework of the system possess a high impact on the structure. The crosssection of the microfluidic fibers suggests the aggregation of LMWG 1 into dimers that in turns, will follow the 1D growth, suggesting that fibers obtained by glucono$\delta$-lactone $\mathrm{pH}$ change will be generated by the assembly of the tapes formed by dimers.

\section{Conclusion}

Understanding the fibrillation mechanism of low molecular weight hydrogelator (LMWG) is crucial for designing novel materials with a wide variety of applications.

Microfluidic devices offer the possibility to resolve the spontaneous fibrillation mechanism at the earlier stages in a steady fashion for self-assembled LMWG systems. Several aggregation rates can be explored by flowing different LMWG concentrations as well as different $\mathrm{pH}$ solutions. Moreover, the use of diffusive mixing can led to new pathways in self-assembly processes of low and high molecular weight organic or biological compounds. 
The current work shows that selfassembly of LMWG can be enhanced and controlled using $\mathrm{pH}$ jumps obtained by diffusive mixing in microfluidic devices. As the two fluids with different $\mathrm{pHs}$ merge (early stages), controlled self-assembly of LMWG lead to aggregates with crosssection of about $2 \mathrm{~nm}$, sensibly smaller than the aggregates obtained by standard mixing in a vial using controlled $\mathrm{pH}$ change via glucono- $\delta$-lactone. With increasing diffusion time elapsed, aggregates were growing in size and numbers and occupy the channel space whilst flowing unperturbed. Our results show that early stages of molecular aggregation can be successfully studied using synchrotron radiation and new generation microfluidic chips with low background scattering allowing to study self-assembly in diluted system of low-molecular weight molecules.

Importantly, shear effects on self-assembled fibrillar morphologies can be studied in microfluidic devices. Multi-step reactions to modify the morphology of the self-assembled LMWG fibers as well as the generation of bubbles with internal structure (LMWG fibers), can also be achieved by introduction of further channels in the microfluidic devices that possess promising applications such as such as wound treatment, tissue engineering and drug delivery.

[1] P. Terech, G. R. Weiss, Molecular Gels: Materials with Self-Assembled Fibrillar Networks, Springer, Dordrecht, The Netherlands 2006.

[2] P. Terech, D. Pasquier, V. Bordas, C. Rossat, Langmuir 2000, 16, 4485.

[3] P. Terech, A. D. Geyer, B. Struth, Y. Talmon, Adv. Mater. 2002, 14, 495.

[4] P. Terech, G. R. Weiss, Chem. Rev. 1997, 97, 3133.

[5] X. Y. Liu, P. D. Sawant, Adv. Mater. 2002, 14, 421.
[6] D. J. Adams, M. F. Butler, W. J. Frith, M. Kirkland, L. Mullen, P. Sanderson, Soft Matter 2009, 5, 1856.

[7] R. T. Woodward, L. Chen, D. J. Adams, J. V. M. Weaver, J. Mater. Chem. 2010, 20, 5228.

[8] D. J. Adams, L. M. Mullen, M. Berta, L. Chen, W. J. Frith, Soft Matter 2010, 6, 1971.

[9] A. Aufderhorst-Roberts, W. J. Frith, A. M. Donald, Soft Matter 2012, 8, 5940.

[10] F. M. Menger, K. L. Caran, J. Am. Chem. Soc. 2000, 122, 11679.

[11] I. W. Hamley, Angew. Chem. Int. Ed. 2007, 46, 8128. [12] C. Yan, D. J. Pochan, Chem. Soc. Rev. 2010, 39, 3528.

[13] I. W. Hamley, Soft Matter 2011, 7, 4122.

[14] D. Zhao, J. S. Moore, Org. Biomol. Chem. 2003, 1, 3471.

[15] L. Pollack, M. W. Tate, N. C. Darnton, J. B. Knight, S. M. Gruner, W. A. Eaton, R. H. Austin, Proc. Natl. Acad. Sci. U.S.A. 1999, 96, 10115.

[16] J. S. Lee, E. Um, J.-K. Park, C. B. Park, Langmuir 2008, 24, 7068.

[17] R. Russell, I. S. Millett, M. W. Tate, L. W. Kwok, B. Nakatani, S. M. Gruner, S. G. J. Mochrie, V. Pande, S. Doniach, D. Herschlag, L. Pollack, Proc. Natl. Acad. Sci. U.S.A. 2002, 99, 4266.

[18] N. T. Nguyen, S. Wereley, Fundamentals and Applications of Microfluidics, Artech House, Boston 2006.

[19] W. Li, J. Greener, D. Voicu, E. K. Lab Chip 2009, 9, 2715.

[20] G. Portale, D. Cavallo, G. C. Alfonso, D. HermidaMerino, M. v. Drongelen, L. Balzano, G. W. M. Peters, J. G. P. Goossens, W. Bras, J. Appl. Cryst. 2013, 46, 1681.

[21] F. Rodŕguez-Llansola, B. Escuder, J. F. Miravet, D. Hermida-Merino, I. W. Hamley, C. J. Cardin, W. Hayes, Chem. Commun. 2010, 46, 7960.

[22] M. Trebbin, D. Steinhauser, J. Perlich, A. Buffet,

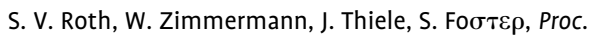
Natl. Acad. Sci. U.S.A. 2013, 110, 6706.

[23] M. E. Brennich, J.-F. Nolting, C. Dammann, B. Nöding, S. Bauch, H. Herrmann, T. Pfohl, S. Köster, Lab. Chip 2011, 11, 708.

[24] F. Rodŕguez-Llansola, D. Hermida-Merino, B. Nieto-Ortega, F. J. Ramírez, J. T. L. Navarrete,

J. Casado, I. W. Hamley, B. Escuder, W. Hayes, J. F. Miravet, Chem. Eur. J. 2012, 18, 14725.

[25] J.-L. Li, X.-Y. Liu, Adv. Funct. Mater 2010, 20, 3196. [26] R. Wang, X.-Y. Liu, J. Xiong, J. Li, J. Phys. Chem. B 2006, 110, 7275 . 